\title{
A Smart Way of Coping with Common Core Challenges - Introduction to CAFA SmartWorkbook
}

\author{
Jaehwa Choi (Corresponding author) \\ Assessment, Testing, and Measurement \\ Department of Educational Leadership, The George Washington University \\ 2134 G Street NW \#106, Washington, DC 20052, USA \\ Tel: 1-202-944-2602Ｅ-mail: jaechoi@gwu.edu

\begin{abstract}
Miseon Kang
Assessment, Testing, and Measurement, The George Washington University 2134 G Street NW \#106, Washington, DC 20052, USA

E-mail: avecmiseon@gwu.edu
\end{abstract}

Najung Kim

Department of Educational Leadership, The George Washington University 2134 G Street NW \#106, Washington, DC 20052, USA

E-mail: najungkim609@gmail.com

William Dardick

Assessment, Testing, and Measurement, The George Washington University 2134 G Street NW \#105, Washington, DC 20052, USA

E-mail: wdardick@gwu.edu

Xinxin Zhang

University of Alberta

116 St. and 85 Ave., Edmonton, AB, Canada

E-mail: xinxin4@ualberta.ca 
Received: October 1, 2015 Accepted: November 5, 2015

Published: November 12, 2015

doi:10.5296/jei.v1i2.8381

URL: http://dx.doi.org/10.5296/jei.v1i2.8381

\begin{abstract}
The Common Core State Standards (CCSS) in mathematics are currently adopted in most U.S. states. Nonetheless, most math teachers across the country are still experiencing difficulties in putting these standards into practice. Teachers and local school administrators are faced with a challenge of adapting methodologies in instruction and assessment to ensure that students master the knowledge and skills required in the new standards. This leads to an urgent need for well-designed teaching and assessment tools for math education that are aligned to the CCSS.
\end{abstract}

The purpose of this paper is to illustrate the Computer Adaptive Formative Assessment (CAFA) SmartWorkbook which is an Information and Communication Technology (ICT) based teaching and assessment tool specially designed for coping with challenges in implementing the CCSS in mathematics. The CAFA SmartWorkbook represents a new stage in exploring opportunities in educational innovation, capitalizing on advances in assessment and technology. This system can be an effective solution to cope with CCSS challenges in both theoretical and practical points of view for students, teachers, parents, and educational administrators.

Keywords: Common Core State Standards, Formative assessment, Computer adaptive testing, Computer assisted learning, Auto item generation, Computer Adaptive Formative Assessment, Math education

\title{
1. Introduction
}

Nearly every state in the U.S. has begun implementing the Common Core State Standards (CCSS; Williams, 2012) in mathematics, while many math teachers are still unsure how to effectively put these standards into practice. Teachers and local school administrators need to make fundamental changes in how they teach math in order for students to master the knowledge and skills required in the new standards.

There is an urgent need for well-designed teaching tools in math that are aligned to the CCSS (Kornhaber, Griffith, \& Tyler, 2014). For example, there is a need at middle school level for tools in mathematics driven by the expectations of what a student can do. Students are expected to compute with fluency, work with algebraic expressions, solve real-world geometry problems, build an understanding of statistics and probability, and learn other challenging math content in the CCSS. A 2013 survey of more than 400 middle school math teachers by the University of Rochester found that slightly over two-thirds of the teachers surveyed are using textbooks adopted prior to the CCSS (Davis, Choppin, Roth, \& Drake, 2013). The study further states that one-third of the teachers cited a need for more support, 
including better-aligned curriculum materials, in implementing the math CCSS. In the absence of these materials, over $60 \%$ of the teachers surveyed reported regularly accessing online resources, and others are creating their own curriculum materials. Creating classroom assignments for middle school math aligned to the CCSS is a demanding and time-consuming task, more so when considering the complexity of knowledge and skills embodied in the standards for those grades.

In recent years there has been a general consensus on a number of challenges associated with CCSS. First, there has been an unsuccessful campaign in articulating to parents, teachers and the general public what the students are expected to learn under the CCSS. Primarily this challenge can be tied to a lack of sufficient information being provided to these critical stakeholders. Second, CCSS are not fully aligned to textbooks, digital media and curricula to meet the international standards. Third, there is a gap in available resources for professional development of educators on identified needs and best practices of CCSS. Lastly, an assessment system to measure student performance against the standards is not fully ready to be implemented in practice. This makes assessment data inaccurate which leads to challenges in related policy changes (Williams, 2012; Shanahan, 2013).

The assessments currently being designed by state consortia and others to measure students' mastery of CCSS are primarily summative, in that they are intended to evaluate students' overall proficiency for accountability purposes or to quantify how much students have learned during the year. While summative assessment is certainly useful, it often leaves a teacher scrambling for specific content to help students with different needs. These assessments are unlikely to provide the kind of value added information of formative assessment, which are integrated into classroom practice. Teachers need formative assessment in order to pinpoint students' challenges in mastering specific standards and to individualize instruction to help each student overcome particular difficulties. It is imperative to have a genuine formative approach which inherently adapts the contents with which the students are struggling to simultaneously review the student's capabilities and provide timely feedback/treatment for strengthening their weak areas.

The CAFA SmartWorkbook (Choi, Kim, \& Yoon, 2014b), an ICT based assessment tool specially designed for coping with challenges in implementing the CCSS in mathematics, has recently been developed based on an ICT Assessment Engineering platform called the Computer Adaptive Formative Assessment (CAFA; Choi, Kim, \& Yoon, 2012) system. The application prototype currently includes an inventory of math problems aligned to one cluster of the math standards in the Common Core.

The primary application of this ICT-based assessment tool is to help fill the need for well-designed classroom assignments with items aligned to the CCSS in middle school math. The CAFA SmartWorkbook can be used as a teaching resource. For example, a teacher can select assignments that are fully aligned to each of the standards in the Common Core math for grades 6 and 7. The assignments are designed to help teachers effectively teach math using methods from the CCSS. The assignments can be used as homework, practice problems, quizzes and other classroom assessments. 
The application has several desirable features not available in many of the existing CCSS-aligned curriculum materials. First, it provides students with several types of built-in support for learning. After students submit an answer to a problem, they can receive immediate feedback on their answers, with detailed steps toward a solution and tips about how to solve the problem. The system can provide additional sets of practice items geared to students' level of knowledge, as well as an automatic reassessment for each standard to help students retain what they have just learned or previously mastered. Second, SmartWorkbook can automatically adapt the difficulty level of problems to an individual student's needs and progress, using a diagnostic and treatment algorithm built into the CAFA system. This makes it possible for teachers to tailor assignments to an individual student's learning needs. Third, the application provides primary stakeholders (e.g. students, parents, and teachers) with instantaneous diagnostic reports about the difficulties students are experiencing in learning. Feedback is instantaneous, enabling teachers to diagnose students' daily progress and identify problem areas tailored to the child in learning specific knowledge and skills in the Common Core math. Fourth, it is flexible to use. It is not necessary for every student to have an individual laptop or desktop to use SmartWorkbook. The assignments can be used online through the web or off-line in a traditional paper format. In addition, students and their parents can access the application with a smart phone or tablets, using the type of Quick Response (QR; Denso Wave Incorporated, n.d.) barcodes that have become commonplace in advertising and shopping. Because the application can be easily accessed on demand regardless of time and location via any mobile devices, it offers a ubiquitous source of curriculum material, assessment items, and diagnostic information.

This paper introduces the CAFA SmartWorkbook; a Math workbook, specially developed to cope with the Common Core challenges using state-of-the-art technologies by experts in areas of Educational Assessment, Computer Science, and Math. Our paper is organized into four main sections. First we briefly review the background of the CCSS and challenges of implementing the CCSS in practice. Next we provide a general overview of formative assessment systems. We then introduce the CAFA system and CAFA SmartWorkbook. Next we review technical components that illustrate benefits of the CAFA system and CAFA SmartWorkbook. We close this manuscript with a discussion of the implications of the system and future work from three different perspectives: Educational Policy, Educational Practice, and Educational Technology.

\section{Common Core State Standards}

\subsection{Common Core State Standards}

According to the Common Core State Standards Initiative (2015) "The Common Core is a set of high-quality academic standards in mathematics and English language arts/literacy (ELA). These learning goals outline what a student should know and be able to perform at the end of each grade. The standards were created to ensure that "all students graduate from high school with the skills and knowledge necessary to succeed in college, career, and life, regardless of where they live". The main purpose of CCSS is to identify the most essential skills and knowledge that students should have, not the way in which they acquire them (Rothman, 
2011). Under the CCSS, students will be held to the same standards, which is one of the essential issues for educational equity. The standards provide common goals in terms of increased skill levels that students will need in order to be competitive in the $21^{\text {st }}$ century world. The implementation of the CCSS is a state-led effort. The creation of the standards brings public educators from across the nation together to share the expertise and common values, which are so important for citizen participation in a democratic society (Williams, 2012; Shanahan, 2013; South Pasadena Unified School District, 2014-2015).

\subsection{Challenges in CCSS}

Since its inception, many challenges have been identified in the implementation of CCSS (Greene, 2012; Toscano, 2013). There was a disconnect in communicating to parents, teachers, and the general public what students are expected to learn. Parents and teachers are still experiencing difficulties in understanding the value of CCSS and how to use the CCSS primarily due to a lack of stakeholder information and resources for teachers. CCSS is not yet fully aligned to textbooks, digital media and curricula to meet the international standards. Many textbooks are only partially aligned to CCSS. There is a need for professional development on identified needs and best practices related to CCSS. Without this resource, teachers are not able to fully understand and incorporate the new standards into their teaching. There is also needs for a working assessment system that could evaluate student performance against the standards. This misalignment leads to inaccuracy in assessment data which hinders policy changes.

\section{Assessment Systems}

\subsection{Forms of Assessment}

Formative assessment is a compilation of observed tasks and behaviors designed to promote student learning by altering educational activities through a feedback mechanism between teacher/student (Carnegie Mellon University, 2015). Effective assessment of student performance in math as well as in other subjects can be as important as teaching standards. Assessment provides teachers and policy makers with important information about student achievements and gaps in learning (Boston, 2002). Along with the positive features of assessment there are limitations of the usefulness of acquired information. Despite the efforts of many teachers to develop tests that assess critical thinking and understanding of the material, some tests are still designed to encourage superficial learning. Tests can encourage competition among students rather than promote individual improvement. Assessments often fulfill administrative requirements rather than identify specific needs of the student (Birenbaum et al., 2006; Black \& William, 1998a; Black \& William, 1998b).

There are different forms of assessment beyond the formative model of student teacher feedback. When we think of the "traditional assessment" we are likely considering the evaluation that occurs at the end of learning module that is intended to encapsulate the summation of student work and compare it to an external criterion (2015). These high stakes assessments are summative assessments, while low stakes assessments are often formative in nature. High stakes summative assessment can occur in the classroom setting or be more 
formalized in standardized tests, such as those required by legislation (i.e. No Child Left Behind $[N C L B], 2002)$. Traditional assessment based on legislation is driven by curricula content. States determine the knowledge and skills that a student must learn in each grade, and then the student must complete an assessment designed to measure his or her understanding of this knowledge and skill set (Mueller, n.d.). These assessments have been criticized for covering a very limited range of content at a very superficial level (Senk, Beckman, \& Thompson, 1997). It also should be noted that when assessments are presented in the classroom setting it may be difficult or impossible to parse out the goal of assessment simply from the structure of the test.

There exists tension between classroom-based formative assessments of student learning, and the highly visible and large-scale national or regional summative assessments of student performance. The latter of which are often intended to hold schools accountable for meeting standards, and may hold particular consequences for low or underperforming schools. Highly visible summative tests are often used to hold schools accountable for student achievement and drive what happens in classrooms. There is disconnection between the value of information gathered by the large-scale summative approach and formative classroom-based approach to assessment and evaluation. Information gathered through national regional or school-based monitoring is seen as irrelevant or unhelpful to the business of teaching.

Similarly, information gathered in classrooms is seen as irrelevant to the business of policy making (Tiknas \& Sutton, 2006). According to a study on Assessment in Education by Tiknas and Sutton (2006) teachers lack a clear understanding of the differences between formative and summative assessment. They further attribute this relatively weak understanding as one of the challenges teachers face when they try to develop formative assessment tasks for their classrooms. In considering the requirement and positive aspects of formative assessment, coupled with challenges in the classroom, we introduce a system that can help support the teacher and provide valuable formative feedback.

\section{Computer Adaptive Formative Assessment (CAFA) System}

\subsection{Inception}

With regards to the impact of feedback in computer-based learning system (van der Kleij, 2014), the results that are reviewed in literature are rather mixed. A number of authors have provided positive impact on students' learning outcomes as a consequence of particular ways to provide feedback (Corbalan, Paas, \& Cuypers, 2010; Lee, Lim, \& Grabowski, 2010; Smits, Boon, Sluijsmans, \& van Gog, 2008; Wang, 2011). While other studies have found no or little impact (Clariana \& Lee, 2001; Gordijn \& Nijhof, 2002; Kopp, Stark, \& Fischer, 2008).

Recently, to enable the system-based formative assessment for learning, researchers have developed several ICT applications, such as EAGLE (Enhanced Assessments of Grade-Level Expectations; Louisiana Department of Education, n.d.), ALEKS (Assessment and Learning in Knowledge Space; McGraw-Hill Global Education Holdings, 2014), or PowerSource (Phelan, Vendlinski, Choi, Dai, Herman, \& Baker, 2011). Since many challenges have been identified for schools, parents, and students in coping with CCSS, researchers (Choi, Kim, \& 
Yoon, 2012) developed the CAFA system, a technology-mediated educational learning and assessment system focused on a formative assessment process. The CAFA system is designed to provide individually tailored diagnostics, feedback, and other useful information to students, educators, parents, policy makers, and members of the community.

\subsection{Structure}

CAFA system is composed of a set of important components. First, CAFA system is strictly standard-based which means it is completely aligned with the Common Core standards. Second, it is ICT-based for educational big data analytic system, i.e., all assessment items are electronically managed in the network-based central database system using client-server structure (Farlex Incorporation, 2015). Third, it is built based on an assessment engineering framework equipped with Automatic Item Generation (AIG; Gierl \& Haladyna, 2012; Choi, Kim, \& Yoon, 2014a) system. Therefore, the system can provide nearly a limitless set of assessment items. This assessment system also provides highly interactive and multi-media assessment items using several multi-media technologies, such as parameterized mathematical expression image generation, parameterized chart/figure generation, or text-to-speech. Lastly, CAFA incorporates an accountability system where performance and progress made by students and teachers are closely monitored. Clients of CAFA can use diverse platforms to access CAFA server without having to download all the information - students or teachers can use websites, mobile applications or eBbooks in order to access the server to check out the information they need. Using the information saved on the server, users can create their own version of SmartWorkbook or SmartAssignment which are two examples of client applications using the CAFA system as an engine. They can also work online while connected to the server or print out the materials and work offline using QR (Denso Wave Incorporated, n.d.) codes for instant feedback.

\subsection{Objectives}

Considering the challenges mentioned previously surrounding CCSS and its assessment, CAFA was developed to serve the following objectives. First, it will help articulate to parents, teachers and the general public what the students are expected to learn. Second, CAFA will provide aligned textbooks, digital media and curricula that meet the international standards via a workbook solution, which will be very useful unlike many existing textbooks claim to be aligned with CCSS but in truth present no linking evidence between CCSS and those textbooks. Third, it will also provide a base for professional development for educators on identified needs and best practices via a teacher friendly application and help to implement an assessment system to measure student performance against the Standards via formative assessment system. Lastly, it will help evaluate policy changes needed to help students and educators meet the Standards via research based service.

\section{CAFA SmartWorkbook}

\subsection{Background}

Like other client application using the CAFA engine, such as CAFA SmartAssignment (Choi, Kim, \& Yoon, 2013; Kim, H., Park, J., Jung, Y., Park, S., Kim, C., Lee, C., \& Choi, J., 2014), 
the CAFA SmartWorkbook is also an application using the CAFA engine (or server). The CAFA SmartWorkbook was created (a) in response to challenges identified with CCSS; (b) to maximize the full benefits of CCSS; (c) to be aligned textbooks; and (d) to be aligned of the other assessment systems. The workbook contributes greatly to broadened access to Common Core curriculum by providing the materials and learning tools to users through smart devices.

\subsection{Development}

The CAFA SmartWorkbook was developed by Associate Professor Jaehwa Choi at the George Washington University along with his team members; Professor Sunhee Kim from Howard Community College's mathematics division; and Professor Kyongil Yoon from Notre Dame of Maryland University's computer studies department. The SmartWokrbook is a math workbook which supports both traditional and smart-learning environments for K-12 students in the United States. This interdisciplinary and inter-institute project is expected to contribute to the enhancement of mathematics educational services especially for implementing CCSS. Designed specifically to cope with challenges in implementing CCSS, the workbook is currently available for students, teachers and for $6^{\text {th }}$ grade curriculum. This free and printable workbook, fully aligned with CCSS, integrates smart-learning components. These components can be accessed via any mobile and/or smart devices, and offers instant feedback including detailed solution steps, additional practices on problem areas, as well as diagnostic information. By virtue of these integrations, this workbook will play an extremely important role not only in online education, but also in offline classroom educational practices.

\subsection{Advantages}

First, SmartWorkbook provides students with several types of built-in support for learning. After students submit an answer to a problem, they can receive immediate feedback on their answer, as well as the detailed steps toward a solution or hints about how to solve the problem. The system can provide additional sets of practice items geared to students' level of knowledge, as well as an automatic reassessment for each standard to help students retain what they have just learned or previously mastered. Second, SmartWorkbook can automatically adapt the difficulty level of problems to an individual student's needs and progress, using a diagnostic and treatment algorithm built into the CAFA system. This makes it possible for teachers to tailor assignments to an individual student's learning needs. Third, the application provides students, parents and teachers with instantaneous diagnostic reports about students' difficulties in learning. This feature is particularly useful because the feedback arrives instantaneously and enables teachers to diagnose students' daily progress, as well as their problem areas in learning specific knowledge and skills in the math Common Core. Fourth, from the workbook's versatile nature, it is not necessary for every student to have an individual laptop or desktop to use it. The assignments can be used online through the web or offline in a traditional paper format. In addition, students and their parents can access the application with a smart phone - which most people now have access to-or tablets, using the type of QR barcodes that have become commonplace in advertising and shopping. As the application can be easily accessed on demand regardless of time and location via any mobile devices, it offers a ubiquitous source of curriculum material, 
assessment items, and diagnostic information. This year, Professor Choi's team will expand this service from grades 6 and 7 to include grades 3 to 8 with capability of incorporating a multi-lingual version including other languages (e.g., Chinese, Spanish, and Korean) for students to be prepared and positioned to compete successfully in the global economy.

\subsection{A Solution for CCSS Challenges}

This application helps fill the need for well-designed classroom assignments and assessment items aligned to the CCSS in middle school math. This application includes assignments that are fully aligned to each standard in the Common Core math for grades 6 and 7 (grade expansion in process) and are developed to help teachers effectively teach math using new methodologies proposed in the CCSS. These assignments can be used as homework, practice problems, quizzes and other classroom assessments. In particular, because the CAFA SmartWorkbook is designed to overcome the challenges of CCSS in practices, it can be a useful resource to help teachers, students, and parents who are facing difficulties in applying CCSS. Five major benefits of the workbook are herein illustrated in more detail.

First, the CAFA SmartWorkbook is fully aligned to CCSS. Unlike other math assessment materials and workbooks that are partially (e.g., only about 30 percent) aligned to CCSS, this workbook strictly and fully covers all CCSS and all assessment items are carefully developed to be aligned to each standard. Inside of the workbook, the practice page contains at least four practice problems which are specifically designed for a particular standard. Furthermore, for grades 6 and 7, all standards were covered in the workbook.

Second, by virtue of being fully aligned to CCSS, this workbook helps to articulate to parents, teachers and the general public what the students are expected to learn. Each standard practice page in the workbook contains a description of each standard, practice problems, results, and assessment feedback is organized, referenced, and linked by standard information. These features of the workbook will help parents and teachers better understand the information and/or value of the CCSS and how to use and benefit from it.

Third, this workbook can be a base for professional development for educators on identified needs and best practices. By virtue of covering all standards with fully functioning ICT features, this workbook can be a great tool for understanding CCSS. Therefore, this workbook can help teachers struggling to use CCSS as the base of professional development where they lack resources. Such resources, which are crucial in understanding the new standards and being able to utilize and incorporate them into their teaching, are either not yet developed or not available to all teachers. In these cases the workbook can act as such a resource.

Forth, this workbook system can be extended toward an assessment system to measure student performance against the standards. Educational activities within this workbook, such as answering on a practice test, can be turned into and saved in the server within the ICT environment as part of the assessment information. Using such saved information, it is possible to inform students' learning progress on particular standards. This year, approximately 12 million students will be assessed against the new standards by large groups 
and associations that are delegated to carry out the assessment. However, they are not fully ready to implement formative assessment due to gaps between the technological advancements and the practical assessment system in use. In sum, this workbook can improve the accuracy of assessment data via the synergetic integration of ICT and psychometric techniques in a workbook application which also has much broader impact capability.

Lastly, this workbook can provide valuable information to evaluate policy changes needed to help students and educators meet the standards. Once collected, saved, and analyzed inside of a server in ICT environment, such assessment information can be used as an efficient tool to monitor and evaluate students' progress and achievement on the standards. Policy makers and evaluators can use the results of such analysis to evaluate and develop policies to improve students' learning.

\section{Features of the SmartWorkbook}

We now introduce and demonstrate various useful features of the SmartWorkbook. Most importantly, individuals can use SmartWorkbook to practice a specific standard with various practice questions, take an exam, submit answers, and receive a report card with a diagnosis immediately after submitting their answers (Choi, Kang, \& Kim, 2014).

\subsection{Getting Started}

As shown in Figure 1, by accessing the website at http://SmartWorkbook.CAFALab.com, users can create their own workbook by selecting grade, domain and cluster level. Upon receiving the workbook through email, users can choose to work online or have the workbook printed to work offline. 

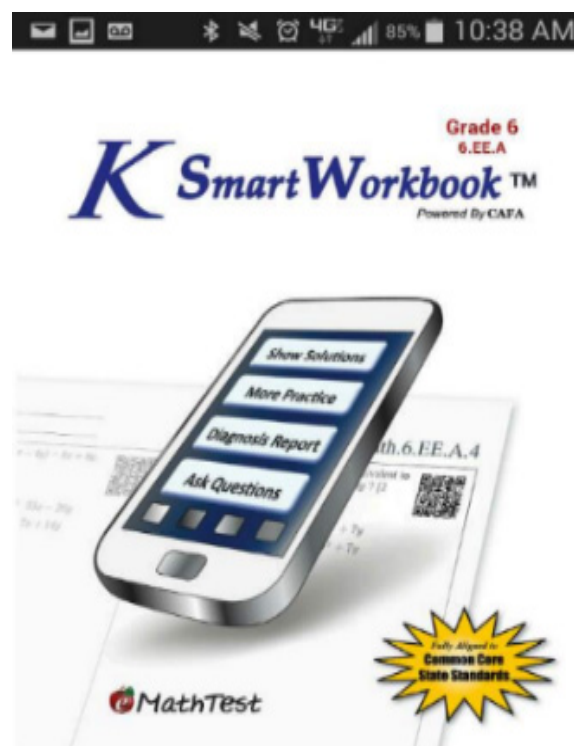

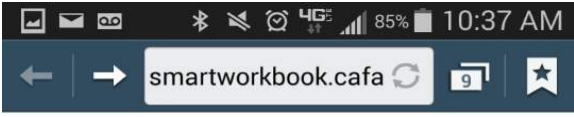

CAFA Smart Workbook $^{\text {тм }}$

Select a Grade/Domain/Cluster

Grade: Not Selected _4

Domain: All domains

Cluster: All clusters

E-Mail: sfutures@yahoo.com

Send a Workbook to My eMail

Figure 1. CAFA SmartWorkbook: Creating a new account

Note. Reprinted from CAFA SmartWorkbook, 2014, Retrieved from February 23, 2015 from http://SmartWorkbook.CAFALab.com/. Copyright 2015 by CAFA Lab Incorporation. Reprinted with permission.

\subsection{Practice Page}

As shown in Figure 2, the first page that a user will see, when opens the workbook, will be this Practice Page which contains practice problems for a certain standard. Practice problems' numbers and figures that are used in the questions have been generated according to the specifications that the user has provided. And on the top right corner of each item, users will see a QR code. 


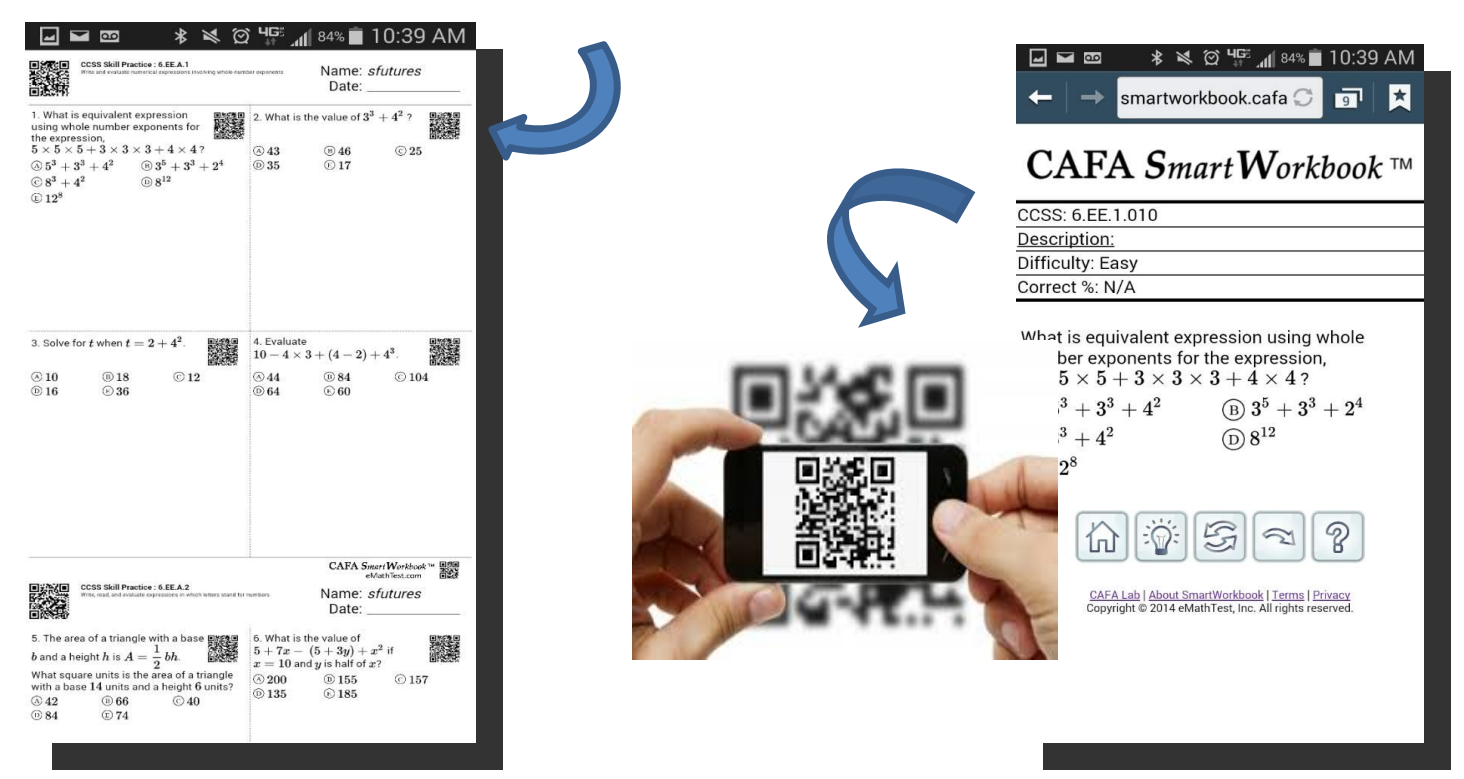

Figure 2. CAFA SmartWorkbook: Accessing practice page, scanning a QR code to access item page

Note. Reprinted from CAFA SmartWorkbook, 2014, Retrieved from February 23, 2015 from http://SmartWorkbook.CAFALab.com/. Copyright 2015 by CAFA Lab Incorporation. Reprinted with permission.

\subsection{Item Practice Page}

As shown in Figure 2, by using a smart device, users can scan each item's QR code (Denso Wave Incorporated, n.d.) which will take them to a specific item page. In this page, users can access various additional information such as the common core standard information for the item, item difficulty, item correct $\%$, etc. 

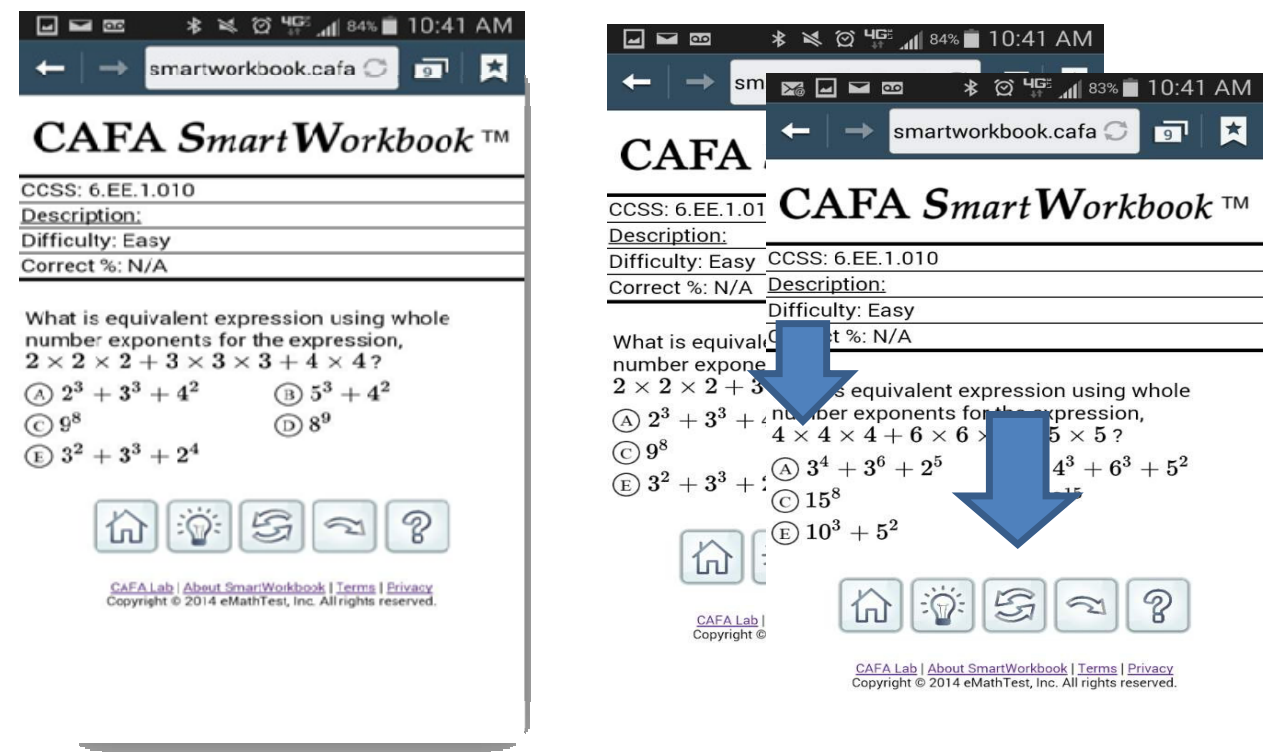

Figure 3. CAFA SmartWorkbook: Checking answers and practicing variants

Note. Reprinted from CAFA SmartWorkbook, 2014, Retrieved from February 23, 2015 from http://SmartWorkbook.CAFALab.com/. Copyright 2015 by CAFA Lab Incorporation. Reprinted with permission.

\subsection{Checking Answers}

At the bottom of each item box, as shown in Figure 3, users will see five different icons. By clicking the second icon which resembles a light bulb, users can see Correct Answer and Solution Steps for the item. All items contain up to ten solution steps that illustrate step by step process of solving the problem.

\subsection{Practicing Variants and Other Items}

As shown in Figure 3, the two arrows icon demonstrates one of the paramount features of the SmartWorkbook. By clicking this button, the system will generate problems with the same pattern but with different numbers and figures which will help students understand and master the specific item. Note that this particular workbook feature was strongly appreciated and endorsed in practice. An empirical experiment research conducted in a South Korea high school as a pilot-test of the workbook application and its features. In this pilot test, the students and teachers feedback in the focus group analysis result showed that this feature was the most important and attractive feature of the workbook (H. Kim, J. Park, Jung, S. Park, C. Kim, Lee, \& Choi, 2014). By clicking the one arrow icon, users can access other items that also fall under the same standard to further master the standard.

\subsection{Asking Questions}

By clicking the question mark button from the menu bar, students can send questions to 
system operators. Once the button has been clicked, a question box will pop up at the bottom of the page. Students can then write their question in the box and click "send question" button to send the inquiries to the system operators.

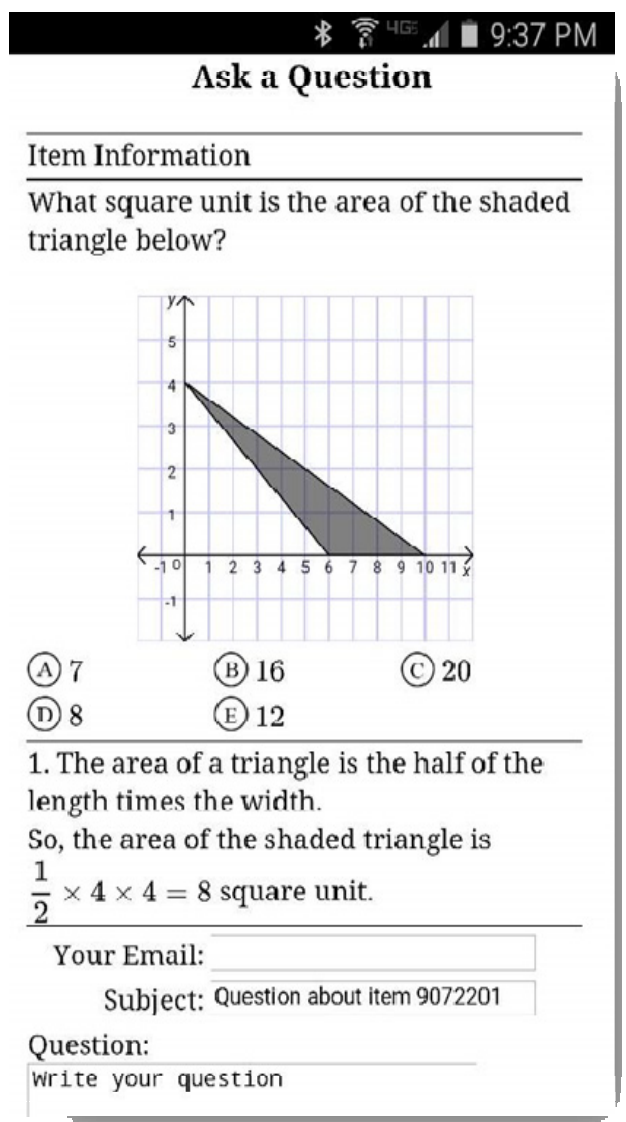

Figure 4. CAFA SmartWorkbook: Asking questions

Note. Reprinted from CAFA SmartWorkbook, 2014, Retrieved from February 23, 2015 from http://SmartWorkbook.CAFALab.com/. Copyright 2015 by CAFA Lab Incorporation. Reprinted with permission.

\subsection{Taking a Test}

The working application also provides assessment function. Once students feel ready to take a test on a cluster or domain of CCSS, they can take a test in an exam mode page. After they solve problems, by scanning the exam page QR code with a smart device, users will be able to access the page where they can submit answers. 


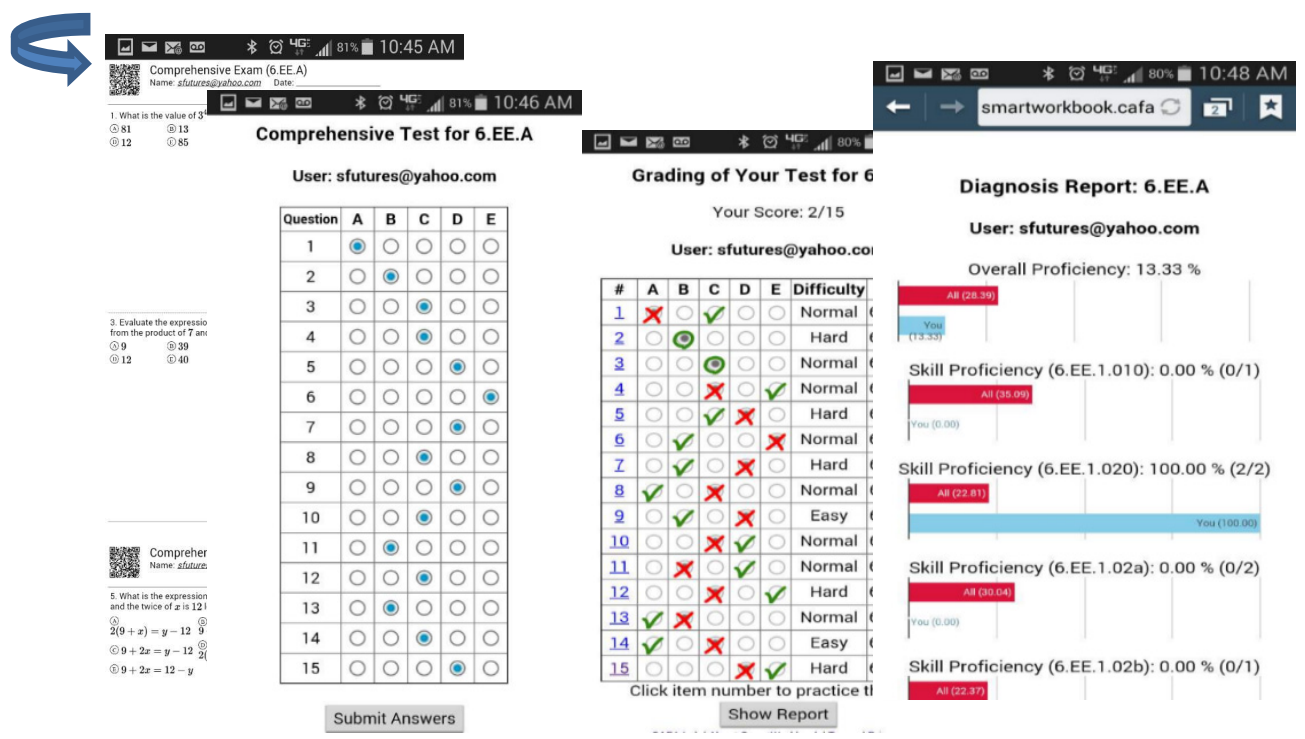

Figure 5. CAFA SmartWorkbook: Taking a test and receiving report cards

Note. Reprinted from CAFA SmartWorkbook, 2014, Retrieved from February 23, 2015 from http://SmartWorkbook.CAFALab.com/. Copyright 2015 by CAFA Lab Incorporation. Reprinted with permission.

\subsection{Checking Answers \& Report Card}

Once students have submitted their answers, they can immediately check their final score. By clicking on each item number, they can access a page where they can find more similar questions. By clicking the "Show Report" button, users can instantly see their scores, unlike other traditional reports that usually take a few weeks to a few months. The report card is provided with various types of diagnostic information prepared based on students' performance.

\section{Discussion}

The purpose of this paper was to introduce the CAFA SmartWorkbook, a Math workbook, tailor-made to cope with the Common Core challenges by using state-of-the-art technologies designed by experts in areas of Educational Assessment, Computer Science, and Math. In the previous parts of this paper, we reviewed the background of the CCSS and the challenges of implementing the CCSS in practice. We also examined how the CAFA SmartWorkbook can be an effective solution to cope with such challenges in both theoretical and practical points of view for students, teachers, parents, and educational administrators. We also reviewed technical components of this system focusing on identifying which specific technologies have been used to bring forth the benefits of the workbook.

Educational assessment is a crucial part of the quest for educational innovation and improvement. By appropriately analyzing educational assessment information, stakeholders 
in education are able to monitor how well students are achieving and whether students and institutions are progressing toward the educational goals that have been set, e.g., implementing CCSS. We have noted the lack of resources for educational stakeholders in implementing CCSS. Additionally, the goals to inform and improve education through assessment are limited by current educational practices.

Educational assessment, the technological infrastructure and monitoring of achievement have dramatically changed over the last century. It is clear that such advances interact with the applied challenges in educational practice regarding CCSS. Although monitoring has been a crucial component of evaluating the educational system, advances in ICT and futuristic assessment can provide information beyond the current practices.

There is a great deal of information regarding the future of assessment, in terms of its elements, rules, and guidelines that can be used to develop and use them. But there remains the need for knowledge and skills to be further analyzed to provide clear guidance for an assessment framework. For example, further domain analysis is necessary for the CAFA SmartWorkbook to incorporate subjects other than math. The CAFA SmartWorkbook components should be further developed to be connected to large-scale accountability systems and to be linked to other learning applications beyond the workbook scope, such as textbook, game-based learning, muli-media learning, etc.

It would be highly valuable if educational stakeholders could come to an agreement on the current assessment system (including tools, resources and assessment) information, even though it may have some limitations. Integrating the advances in educational assessment and technology will provide more informed benchmarks for valid and supportive assessment. It is important to provide students and teachers with practical and efficient tools. Further we should recognize the need to fairly and effectively measure students' learning information from multi-sources, assembled to high level standards such as those described in the CCSS.

Evidence drawn from formative assessment (such as learning profiling information on multiple components of achievement level) is more useful and meaningful in practice when compared to summative assessment results such as overall performance scores. Future challenges the CAFA SmartWorkbook intends to consider include various aspects of knowledge and competence above and beyond overall test scores or performance data. For example, the future system could be an integrated framework to analyze (a) how students understand and explain concepts; (b) how to solve problems; (c) how to measure state/level of knowing; and (d) how to enable self-paced learning.

We have demonstrated throughout the illustrations of the CAFA SmartWorkbook achieving goals such as those mentioned requires coherent integration of both educational assessments and ICT field. Without such incorporation, we may continue to struggle with the challenges in practice because the results of mismatched analysis may be at best, partially correct, or at worst deceptive or misleading. Whether it be formative or summative orientation of assessments, it is imperative to have sufficient and valid information about what has been learned in order to move toward appropriate next steps for learning progress. 
Given the advancements in education and technology ICT enhanced assessment tools and systems should not just be an option, but rather should be the leading paradigm for future development. The futuristic assessment design should support multidisciplinary and collaborative environment. For example, the system should support all stakeholders (e.g., teachers, administrators, cognitive scientists, subject matter specialists, and psychometricians) so that they can participate collaboratively in the entire assessment process, e.g., from the design process to the final reporting stage.

Finally we considered policy and practice for professional development needed to appropriately operate the new system and to identify how assessment should be developed/used to maximize the quality of educational services. Substantial endeavors are warranted to implement such improvements in educational assessment. Undoubtedly, it is clear that such commitment is crucial for our next generation of teachers as it is evident that the new system will enhance student learning.

\section{Reference}

Birenbaum, M., Breuer, K., Cascallar, E., Dochy, F., Dory, Y., \& Ridgway, J. (2006). A learning integrated assessment system. Educational Research Review, 1, 61-67. http://dx.doi.org/10.1016/j.edurev.2006.01.001

Black, P., \& William, D. (1998a). Assessment and classroom learning. Assessment in Education, 5(1), 7-74. http://dx.doi.org/10.1080/0969595980050102

Black, P., \& William, D. (1998b). Inside the black box: Raising standards through classroom assessment. Phi Delta Kappan, 80(2), 139-148.

Boston, C. (2002). The concept of formative assessment. Practical Assessment, Research \& Evaluation, $\quad 8(9)$. Retrieved February 25, 2015, from http://PAREonline.net/getvn.asp? $\mathrm{v}=8 \& \mathrm{n}=9$

Carnegie Mellon University. (2015). Teaching Excellence \& Educational Innovation. Retrieved October 24, 2015, from https://www.cmu.edu/teaching/assessment/basics/formative-summative.html

Choi, J., Kim, S., \& Yoon, K. (2012). CAFA (v 1.0 Beta) System: Computer Adaptive Formative Assessment System for Educational Services [Computer System]. CAFA Lab, Inc.

Choi, J., Kim, S., \& Yoon, K. (2013). CAFA Smart Assignment (v 1.0 Beta) System: Computer Adaptive Formative Assessment Client Application for School Assignments [Computer System]. CAFA Lab, Inc.

Choi, J., Kim, S., \& Yoon, K. (2014a). CAFA Automatic Item Generation (v 1.0 Beta) System: Computer Adaptive Formative Assessment Client Application for Automatic Item Generation [Computer System]. CAFA Lab, Inc.

Choi, J., Kim, S., \& Yoon, K. (2014b). CAFA SmartWorkbook (v 1.0 Beta) System: Computer Adaptive Formative Assessment Client Application for Common Core Math Workbook [Computer System]. CAFA Lab, Inc. 
Choi, J., Kang, M., \& Kim, N. (2014, December 17). Free Common Core Math Workbook: CAFA SmartWorkbook User Guide [Video file]. Retrieved from https://www.youtube.com/watch?v=8Ey4y09FD5I

Clariana, R. B., Wagner, D., \& Murphy, L. C. R. (2000). Applying a connectionist description of feedback timing. Educational Technology Research and Development, 48(3), 5-21. http://dx.doi.org/10.1007/BF02319855

Common Core State Standards Initiative. (2015). Retrieved October 24, 2015, from http://www.corestandards.org

Corbalan, G., Paas, F., \& Cuypers, H. (2010). Computer-based feedback in linear algebra: Effects on transfer performance and motivation. Computers \& Education, 55, 692-703. http://dx.doi.org/10.1016/j.compedu.2010.03.002

Davis, J., Choppin, J. Roth McDuffie, A., \& Drake, C. (2013). Common Core State Standards for mathematics: Middle school mathematics teachers' perceptions. The Warner Center for Professional Development and Educational Reform, University of Rochester. Retrieved on May 20, 2014, from http:/www.warner.rochester.edu/files/warnercenter/docs/commo ncoremathreport.pdf

Denso Wave Incorporated. (n.d.). What is a $Q R$ Code? Retrieved February 25, 2015, from http://www.qrcode.com/en/about

Farlex Incorporation. (2015). Client-server system. Retrieved February 27, 2015, from http://encyclopedia2.thefreedictionary.com/client-server+system

Gordijn, J., \& Nijhof, W. J. (2002). Effects of complex feedback on computer-assisted modular instruction. Computers \& Education, 39(2), 183-200. http://dx.doi.org/10.1016/S0360-1315(02)00025-8

Greene, K. (2012). Common Core: Facts vs Fiction. Scholastic Instructor, 23-27.

Kim, H., Park, J., Jung, Y., Park, S., Kim, C., Lee, C., \& Choi, J. (2014). Introducing a formative assessment system for supporting individually tailored education (I) - Blueprint of On and Off - line formative assessment system. Korea Institute of Educational Curriculum and Evaluation, Research Report. RRE 2014-9.

Kopp, V., Stark, R., \& Fischer, M. R. (2008). Fostering diagnostic knowledge through computer-supported, case-based worked examples: effects of erroneous examples and $\begin{array}{llll}\text { feedback. } & \text { Medical } & \text { Education, } & \text { 823-829. }\end{array}$ http://dx.doi.org/10.1111/j.1365-2923.2008.03122.x

Kornhaber, M. L., Griffith, K., \& Tyler, A. (2014). It's Not Education by Zip Code Anymore But What is It? Conceptions of Equity Under the Common Core. Educational Policy Analysis Archives, 22(4), 2-26.

Lee, H. W., Lim, K. Y., \& Grabowski, B. L. (2010). Improving self-regulation, learning strategy use, and achievement with metacognitive feedback. Educational Technology 
Research and Development, 58, 1-20. http://dx.doi.org/10.1007/s11423-010-9153-6

Louisiana Department of Education. (n.d.). EAGLE 2.0. Retrieved February 25, 2015, from https://www.louisianabelieves.com/assessment/eagle

McGraw-Hill Global Education Holdings. (2014). ALEKS. Retrieved February 25, 2015, from http://www.aleks.com

Mueller, J. (2015). Authentic assessment toolbox. Retrieved February 25, 2015, from http://jfmueller.faculty.noctrl.edu/toolbox/index.htm

Phelan, J., Vendlinski, T., Choi, K., Dai, Y., Herman, J., \& Baker, E. L. (2011). The Development and Impact of POWERSOURCE: Year 5. Cresst Report, 792, 1-254. Retrieved February 25, 2015, from https://www.cse.ucla.edu/products/reports.php?action= fetch\&id=792\#

Rothman, R. (2011). Something in Common: The Common Core Standards and the Next Chapter in American Education. Cambridge, MA: Harvard Education Press.

Senk, S. L., Beckman, C. E., \& Thompson, D. R. (1997). Assessment and grading in high school mathematics classrooms. Journal for Research in Mathematics Education, 28(2), 187-215. http://dx.doi.org/10.2307/749761

Shanahan, T. (2013). Letting the Text Take Center Stage: How the Common Core State Standards Will Transform English Language Arts Instruction. American Educator, 37(3), 4-11.

Smits, M., Boon, J., Sluijsmans, D. M. A., \& van Gog, T. (2008). Content and timing of feedback in a web-based learning environment: Effects on learning as a function of prior knowledge. Interactive Learning Environments, 16, 183-193. http://dx.doi.org/10.1080/10494820701365952

South Pasadena Unified School District. (2014-2015). Common Core State Standards (CCSS). Retrieved February 20, 2015, from http://www.spusd.net/cms/page_view?d=x\&piid=\&vpid= 1386934499974

Tiknas, Y., \& Sutton, A. (2006). Exploring the role of assessment tasks to promote formative assessment in Key Stage 3 Geography: Evidence from twelve teachers. Assessment in Education, 13(3), 327-343. http://dx.doi.org/10.1080/09695940601035502

Toscano, M. (2013). The Common Core: Far from Home. Academic Questions, 26(4), 411-428. http://dx.doi.org/10.1007/s12129-013-9389-9

Wang, T. (2011). Implementation of web-based dynamic assessment in facilitating junior high school students to learn mathematics. Computers \& Education, 56, 1062-1071. http://dx.doi.org/10.1016/j.compedu.2010.09.014

Williams, C. S. (2012). Just the Facts: Common Core State Standards. Educational Horizons, 90(4), 8-9. 


\section{Macrothink}

Journal of Educational Issues

ISSN 2377-2263

2015, Vol. 1, No. 2

World Wide Web Instructional Committee. (1998-2011). Introduction. Retrieved February 25, 2015, from http://wwwic.ndsu.edu

van der Kleij, F. M. (2014). Computer-based feedback in formative assessment (Unpublished Doctoral Dissertation, University of Twente).

\section{Copyright Disclaimer}

Copyright for this article is retained by the author(s), with first publication rights granted to the journal.

This is an open-access article distributed under the terms and conditions of the Creative Commons Attribution license (http://creativecommons.org/licenses/by/3.0/). 